\title{
Pathogenicity Characterization and Antibiogram of Paratyphoid Isolates from Pigeons in Upper Egypt
}

\author{
Alhussien M Gaber'1, Ahmed I. Ibrahim², Soad A Nasef ${ }^{3}$, Nabila Osman ${ }^{2}$ \\ ${ }^{1}$ Animal Health Research Institute, Assiut branch, Assiut, Egypt \\ ${ }^{2}$ Poultry and Rabbits Diseases, South Valley University, Qena, Egypt \\ ${ }^{3}$ Animal Health Research Institute · National Laboratory for Vet, quality control on poultry production, Cairo, \\ Egypt
}

*Corresponding Author: Alhussien M Gaber, Animal Health Research Institute, Assiut branch, Assiut, Egypt.

\begin{abstract}
In order to detect the incidence, pathogenicity and antibiogram of paratyphoid, this study was carried out on 147 pigeons suspected to be suffering from paratyphoid infections collected from different localities in Assiut province (Upper Egypt) and subjected to post-mortem and bacteriological examinations. The results revealed that eighteen Salmonella strains were isolated. The results of serological identification represented in three serotypes; Salmonella Typhimurium (12 strains), Salmonella Enteritidis (5 strains) and Salmonella Muenster (one strain) in a percentage of $66.6 \%, 27.7 \%$, and $5.55 \%$ respectively. The isolation of Salmonella Muenster is recorded for the first time from pigeons in Egypt.The incidence of Salmonella isolation was $12.24 \%$ in Assiut Governorate. Results of in-vitro sensitivity test of the isolated Salmonella strains to various chemotherapeutic agents indicated that all of the isolated strains of Salmonella were sensitive to amikacin, levofloxacin, and norfloxacin and showed a variable sensitivity to the other tested drugs, while the most of strains were completely resistant against doxycycline and kanamycin. The pathogenicity of Salmonella strains was studied in 45 day-old pigeons. The results revealed that all the three examined Salmonella serotypes were pathogenic to the experimentally infected birds with mortality rates 70\%, 60\%, and 30\% for SalmonellaTyphimurium, Salmonella Enteritidis and Salmonella Muenster respectively. The clinical signs and necropsy findings were typical for paratyphoid. Periodical monitoring of incidence, antibiogram and pathogenicity is crucial for effective control measures.
\end{abstract}

\section{INTRODUCTION}

Salmonellae are one of the most important leading pathogens of food-borne illness throughout the world that pose a significant health hazard to human. Infected poultry are the most frequently incriminated reservoirs of salmonellae that can be transmitted through the food to humans (Clavijoet al., 2006 and Humphrey, 2006). Egypt is the top producer of pigeon meat, with Syria, (Taha, 2003). Since Pigeons (Columba livia) are widely found in urban and rural areas in Assiut-Egypt, and come in close contact with other birds and humans that has raised public health concerns as well as dangers for transmitting salmonellae and their antimicrobial resistance strains among poultry species that may represents warns for economic losses(Mohamed, 2008).

Constituting a common major devastating bacterial disease affecting pigeons is

ARC Journal of Animal and Veterinary Sciences paratyphoid leading to Up to $20 \%-30 \%$ of mortalities that can occur in young ages of pigeons as well as adult birds when their resistance is lowered. This disease is not only responsible for high mortality but also as debilitating factor on the birds in all ages which increases their susceptibility to other diseases and reduces their fertility and hatchability. Even if they do hatch, the squabs become weak and often die in a short-time (Tudor, 1991)

Periodic and up to date monitoring of paratyphoid isolates to detect the virulence, pathogenicity and antimicrobial resistance patterns is essential for any disease control program to be effective. Therefore, this study is aiming to monitor the incidence of paratyphiod salmonellae among pigeon flocks and to detect pathogenicity and the antibiogram of the isolated Salmonella strains to different antimicrobial agents available in the field.

Page | 10 


\section{MATERIALS AND METHODS}

\subsection{Isolation of Salmonellae from the Examined Samples}

A total of 147 freshly dead and sacrificed pigeons suspected to be suffering from paratyphoid infections aged from 1.5 month to 3 years old were collected from different localities at Assiut province, and subjected to postmortem and bacteriological examination; Loopfuls and / or portions from heart blood, lung, intestine, liver, spleen and ovary if present were taken under complete aseptic conditions. All samples were immediately examined bacteriologically. The bacteriological examination was carried out according to (ISO 6579/2002).

\subsection{Identification of the Isolates}

\subsubsection{Morphological Characterization}

Gram's stain method was used for morphological identification (Quinn et al., 2002).

\subsubsection{Biochemical Identification}

Presumptive Salmonella colonies from each selective agar plates were cultured ontoTriple sugar iron agar (TSI) slants, Lysine iron agar slant (LI) and Urea agar slants. Suspected Salmonella colonies that gave typical reaction of Salmonella on TSI agar slant and lysine iron agar slant and were urease negative were checked for purity by sub-culturing onto MacConkey's agar plates and then transferred to nutrient agar slants (Salehiet al., 2005; and Begum et al., 2010).

\subsubsection{Detection of Inva gene Among Examined Salmonella Strains Using PCR}

Primers used for targeting the invAgene of Salmonella to confirm the isolated colonies.

Table1: Shows The reagents and quantities that used for each PCR reaction

\begin{tabular}{|l|l|}
\hline \multicolumn{1}{|c|}{ Reagent } & \multicolumn{1}{|c|}{ Volume $(\boldsymbol{\mu l})$} \\
\hline Sample (Template DNA) & $5 \mu \mathrm{l}$ \\
\hline Primers (forward and reverse). & $1 \mu \mathrm{F}$ and $1 \mu \mathrm{R}$ \\
\hline $\begin{array}{l}\text { Enzyme (DNA polymerase, Taq), dNTPs (A, T, G,C) } \\
\text { Buffer (50mM KCl, 10 mMTris-HCl, 1.5 mM } \\
\text { Mgc12) }\end{array}$ & \\
\hline DNAase free water & $5.5 \mu \mathrm{l}$ 2X PCR Master Mix \\
\hline Total reaction volume & $25 \mu \mathrm{l}$ \\
\hline
\end{tabular}

\section{PCR cycling program (The thermal profile)}

The PCR reaction was performed with an automated thermolcycler T-1 (Biometra ${ }^{\circledR}$ ), using the following cyclic conditions table (2):

Table2: Shows the thermal cyclic conditions of PCR reaction

\begin{tabular}{|l|l|l|l|}
\hline Step & Temperatures & Times & Number of cycles \\
\hline Initial denaturation & $95^{\circ} \mathrm{C}$ & 5 minutes & 1 cycle \\
\hline Denaturation & $95^{\circ} \mathrm{C}$ & 45 seconds & 40 cycles \\
\hline
\end{tabular}

ARC Journal of Animal and Veterinary Sciences 


\begin{tabular}{|l|l|l|l|}
\hline Annealing & $52^{\circ} \mathrm{C}$ & 45 seconds & \\
\cline { 1 - 3 } Extension & $72^{\circ} \mathrm{C}$ & 1 minute & \\
\hline final extension & $72^{\circ} \mathrm{C}$ & 10 minutes & 1 cycle \\
\hline
\end{tabular}

D. Electrophoresis of PCR products: The amplified DNA products from Salmonella specific-PCR were analyzed through electrophoresis on $1 \%$ agarose w/v gels, stained with $0.5 \mathrm{mg}$ ethidium bromide and visualized by UV illumination and photographed with Image Master VDS (Pharmacia Biotech). A current of $80 \mathrm{~V}$ for 2 hours was applied to each gel. Eight micro liter of PCR product mixed with $3 \mu 1$ of $6 \mathrm{X}$ loading dye were loaded onto agarose gel. A $100 \mathrm{bp}$ DNA ladder was used as a marker for PCR products.

\subsection{Serological Identification}

Isolates that were positive to invA gene were subjected to serological identification according to Kauffman white scheme (Kauffman, 1974) by using rapid diagnostic Salmonella antisera sets (Denka Seiken Company, Ltd, Japan).

Determination of $O$ (somatic) Antigens: Separate $\mathrm{O}$ antisera were applied to determine the group of the Salmonella isolates.

Determination of $\mathbf{H}$ (flagella) Antigens: Polyvalent $\mathrm{H}$ antisera for both phase I and phase II were tried in order to determine the complete antigenic formula of the isolates.

\subsection{In Vitro Sensitivity Test}

The sensitivity of the isolates was assessed using 11 antibacterial agents (Norfloxacin (NOR) [10mcg], cefotaxime (CTX) [30mcg], Amikacin (AK) [30mcg], Florfenicol (FFC) [30mcg], Ceftriaxone (CRO) [30mcg],Colistin (CT) $[10 \mathrm{mcg}]$, Levofloxacin (LEV) [5mcg], ceftizoxime (ZOX) [30mcg],ciprofloxacin (CIP) [5mcg], Azithromycin (AZM) [15 mcg], Gentamycin (CN) [10mcg), Danofloxacin (DAN) [5mcg] (Bioanalyse $\left.{ }^{\circledR}\right), \quad$ Enrofloxacin (ENR) [5mg], Doxycycline (DO) [30mg], Kanamycin (K) [30mg] , Cefradine (CE) [30mcg). (Oxoid)using disc diffusion test as described by NCCLS, (2003).

Interpretation of the results was performed according to (clinical and laboratory standards Institute (CLSI), 2007) to determine if the strain is resistant, intermediate, or susceptible to the antibiotics tested.

\subsection{Pathogenicity of Some Salmonella Isolates}

A. Preparation of Bacterial Suspension for
Experimental Infection: Twenty four

ARC Journal of Animal and Veterinary Sciences hours brain heart infusion broth cultures were prepared from each of the chosen Salmonella isolates, (Salmonella Typhimurium, Salmonella Enteritidis and Salmonella Muenster), were standardized to contain $4 \times 10^{8} \mathrm{CFU} / \mathrm{ml}$

B. Experimental Birds: A total of 40 (fortyfive days - old) pigeon squabs were used in this study. On the first day, before the experimental infection random samples of 20 squabs were subjected to bacteriological examination by cloacal swabbing for approval that the birds are healthy and free from salmonellae. All the results were Salmonella negative. The remaining squabs were assumed to be Salmonella free and they were divided into 4 groups, (10 squabs per group) and were separately kept in suitable environment at experimental units, Animal Health Research Institute, Assuit.

$>$ The $1^{\text {st }}$ group was orally infected with $1 \mathrm{ml}$ from overnight Salmonellaenteritidis broth culture containing $4 \times 10^{8} \mathrm{CFU} /$ squab.

$>$ The $2^{\text {nd }}$ group was orally infected with $1 \mathrm{ml}$ from overnight Salmonella Muenster broth culture containing $4 \times 10^{8} \mathrm{CFU} /$ squab.

$>$ The $3^{\text {rd }}$ group was orally infected with $1 \mathrm{ml}$ from overnight Salmonella Typhimurium broth culture containing $4 \times 10^{8} \mathrm{CFU} /$ squab.

$>$ The $4^{\text {th }}$ group was kept as non-infected control group.

- Squabs of all groups were fed on commercial ration and kept under daily observation and under strict isolation for one month.

- The incubation period, Symptoms appeared on the infected squabs and mortality rate in each group were recorded and samples from internal organs of dead squabs in all groups during the experimental period were cultured for bacteriological isolation of Salmonella.

- At the end of the experiment, live birds were slaughtered and examined for bacteriological isolation of Salmonella.

\section{Results}

\subsection{Incidence of Paratyphoid Salmonellae in Pigeons}




\subsubsection{Isolation and Identification of the Suspected Strains}

Salmonella was isolated in pure culture from internal organs of examined dead and sacrificed pigeons.18 samples out of 147 samples were suspected to be positive for the presence of salmonella organisms with a percentage of isolation was $12.24 \%$ in Assiut Governorate after morphological and biochemical identification.

\subsubsection{Detection of Salmonella species in culture using PCR}

All examined Salmonella strains were positive for the presence of invAgene as shown in fig.1.

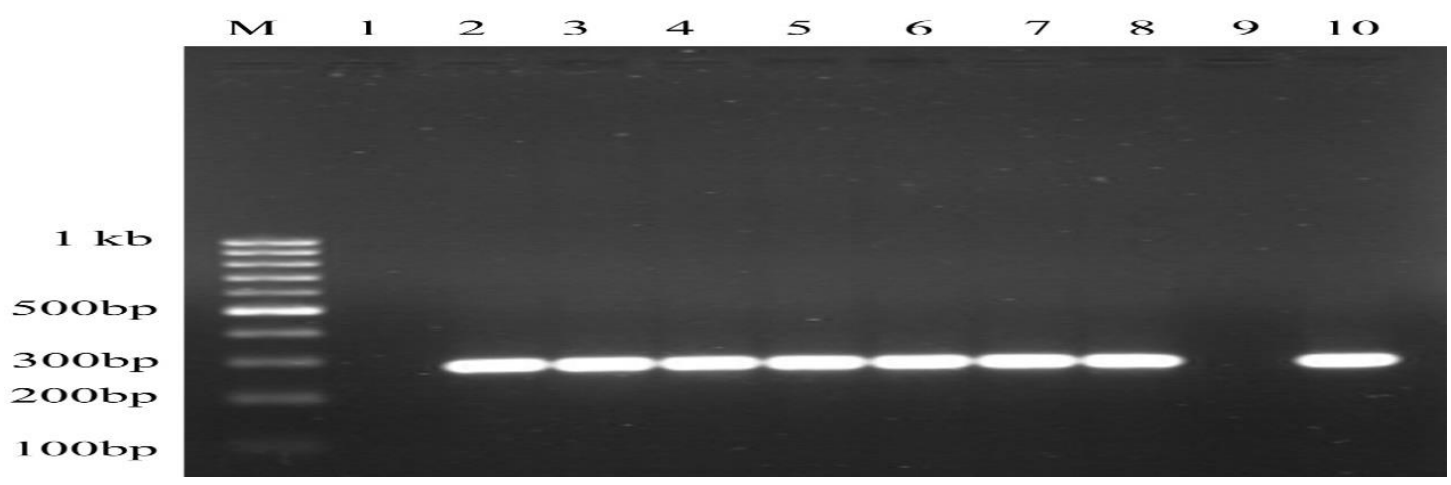

Figure1: Electrophoretic analysis of PCR-amplified target invAgene (284 bp) from different Salmonella isolates. Lane M: 100bp DNA Ladder (Marker). Lanes 1,9 uninoculated, lane 2-8 are strains of Salmonella positive for the presence of invA gene and lane 10 positive control.

\subsubsection{Serological Identification}

Results are shown in fig. (2). All of the Salmonella tested isolates belonged to SalmonellaTyphimurium, SalmonellaEnteritidis and SalmonellaMuenster with the frequency of $(66.6 \%)$ for SalmonellaTyphimurium species, $(27.7 \%)$ for SalmonellaEnteritidis species and $(5.55 \%)$ for SalmonellaMuenster species.

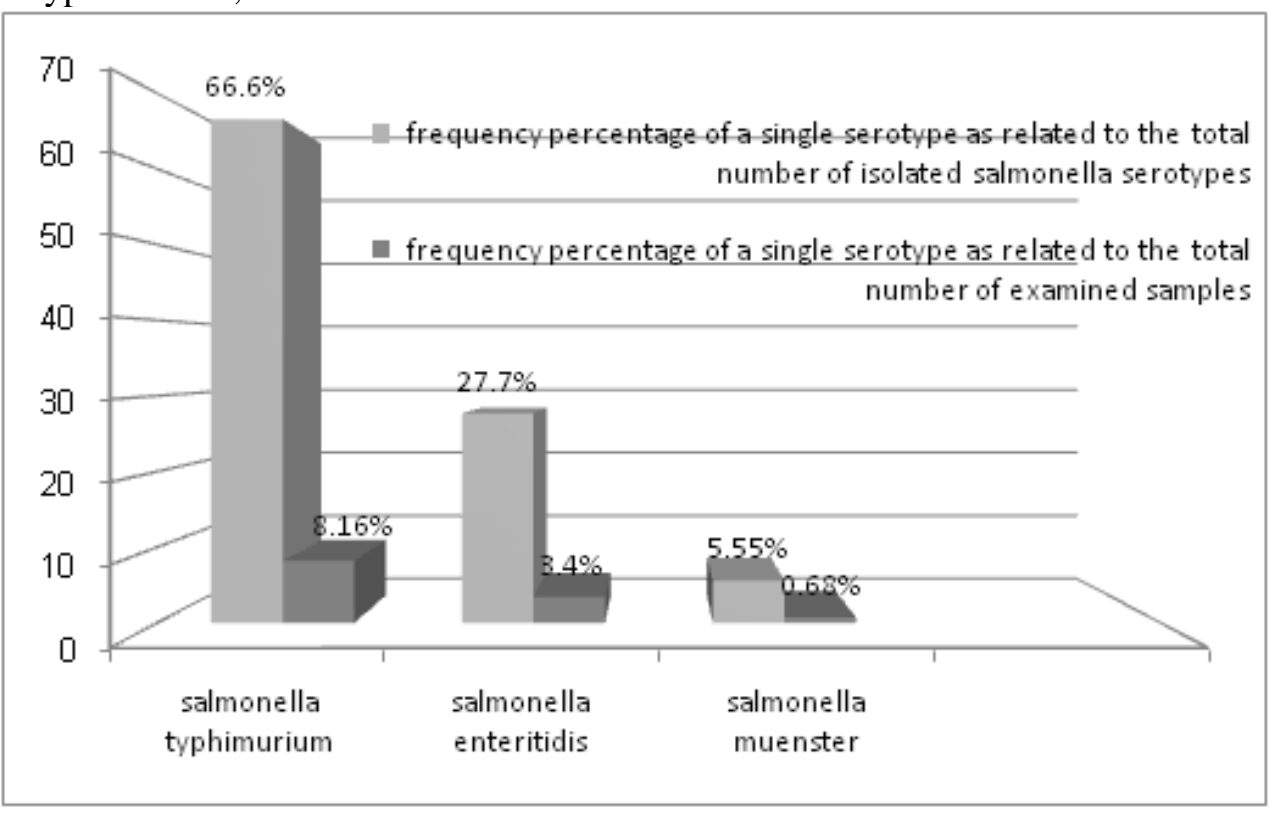

Figure2: The serotyping and frequency percentage of Salmonella sp. isolated from pigeons

\subsection{Antimicrobial Sensitivity Testing (Antibiogram) of Salmonella Isolates from Pigeons}

As shown in fig. 3 SalmonellaTyphimurium strains were completely sensitive $(100 \%)$ to Amikacin and levofloxacin and had a variable sensitivity to Azithromycin (75\%), Norfloxacin (58.34\%) and Gentamycin (41.67\%) .S. Typhimurium strains had intermediate sensitivity to Cefotaxime (83.34\%), Ceftriaxone (58.34\%), Ceftizoxime (58.34\%) and Ciprofloxacin (50\%). While showed a variable degree of resistance to Doxycycline (83.34\%), Kanamycin (83.34\%) and Gentamycin (50\%).

All strains of SalmonellaEnteritidis were completely sensitive (100\%) to Amikacin, levofloxacin and Norfloxacin, and had a variable sensitivity to Azithromycin (80\%) and 
Ceftriaxone (40\%).S. Enteritidis strains had intermediate sensitivity to Ciprofloxacin $(60 \%)$ and Cefotaxime (40\%). While showed a variable degree of resistance to Kanamycin (100\%), Doxycycline (80\%), Gentamycin (80\%), Cefotaxime (60\%), Ceftriaxone $(60 \%)$ and Ceftizoxime $(60 \%)$.
Salmonella Muenster(one strain)was sensitive to Amikacin, levofloxacin, Azithromycin and Ceftriaxone and showed intermediate sensitivity to Cefotaxime, Gentamycin, Ceftizoxime and Doxycycline while showed resistance to Norfloxacin, Kanamycin and Ciprofloxacin.

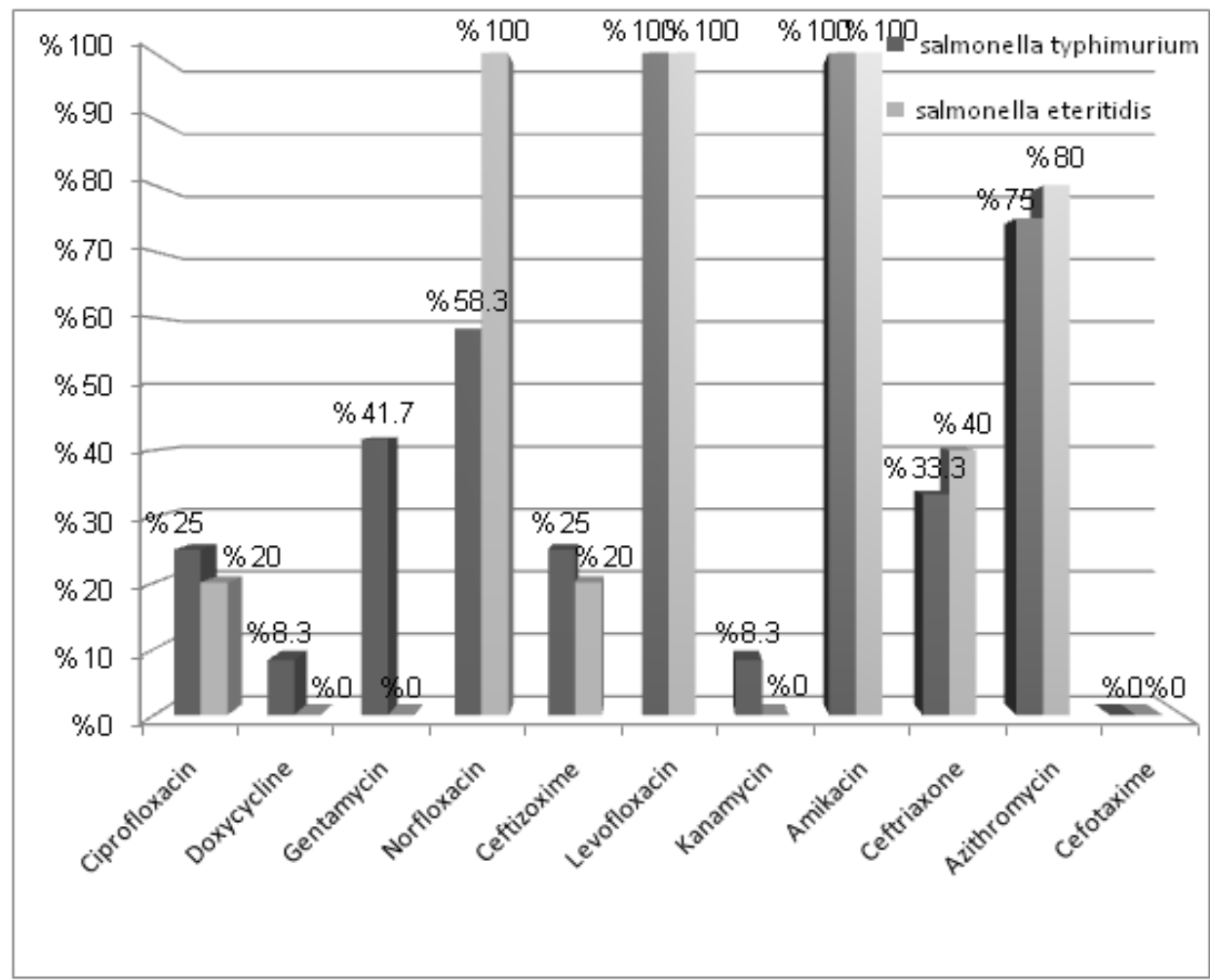

Figure3: The antibiotic sensitivity percentage of Salmonella Typhimurium and SalmonellaEnteritidis isolated from pigeons.

\subsection{Pathogenicity of the Isolated Salmonella Strains in 45-Days Old Squabs}

Incubation Period: The incubation period varied from 4 to 6 days for SalmonellaMuenster, Salmonella Typhimurium and Salmonella Enteritidis respectively. (Table 3).
Clinical Signs: The noticed clinical signs in infected squabs with $S$. Typhimurium, $S$. Enteritidis and Salmonella Muenster were loss of appetite, emaciation, thirsty, ruffled feathers, dullness, greenish diarrhea, pasty vent, huddling together, drooped wings, lameness and later on emaciation was observed (fig. 4).

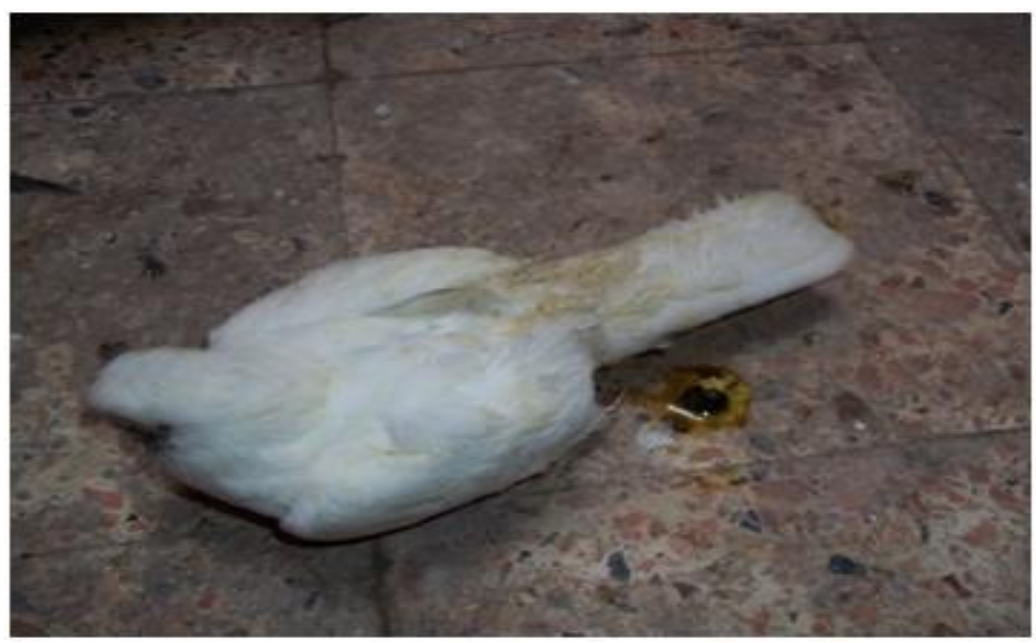

Figure 4: Experimentally infected squab with Salmonella Typhimurium showing greenish diarrhea, shivering, ruffled feathers, and drooping of wings. 
Mortality Rate: The death rates were calculated and it was $70 \%$ for Salmonella Typhimurium infected squabs, $60 \%$ for Salmonella Muenster infected squabs and 30\% for SalmonellaEnteritidis infected squabs table 3.

Post-Mortem Changes: The post-mortem findings were congestion of liver, heart blood vessels and kidneys, catarrhal to severe haemorrhagic enteritis with enlargement of the liver. Greenish-brown and Bronzy discoloration of the liver (Fig. 5) in some cases was also observed. In advanced stage of infection appeared pale areas of focal necrosis on the liver surface, fibrinousperihepatitis and pericarditis ranged from mild to severe form were also observed

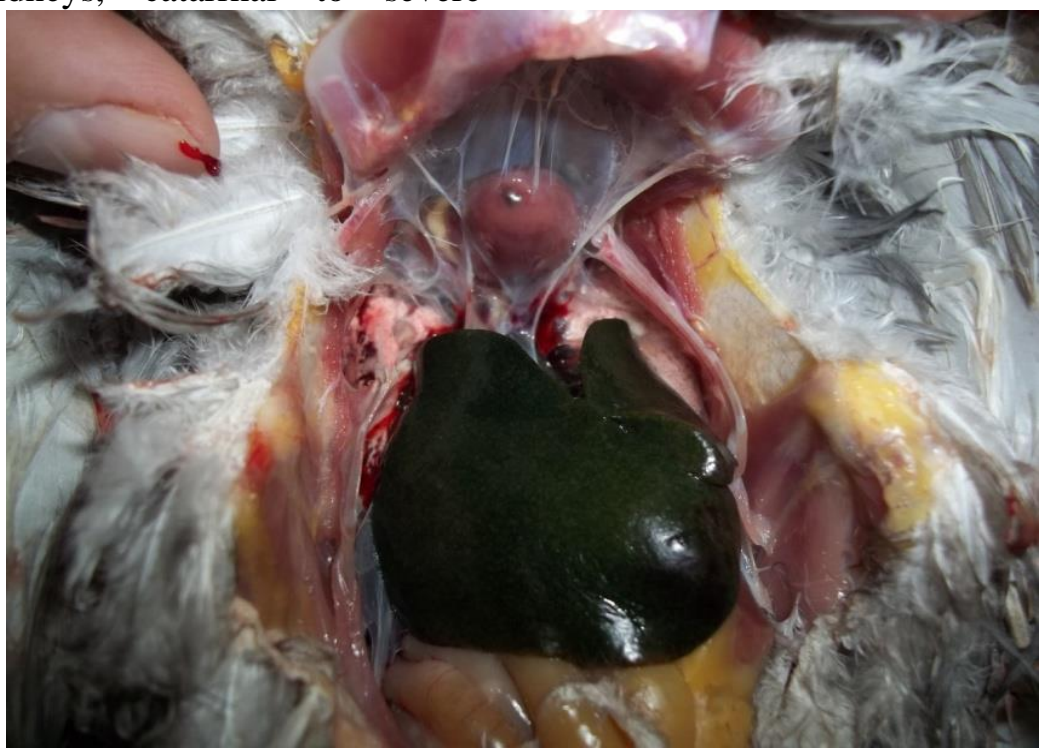

Figure5: experimentally infected squab with SalmonellaTyphimurium showing enlargement of the liver with greenish-brown discoloration (bronzen colored liver) and pericarditis.

Table3: Pathogenicity of Salmonella Typhimurium, SalmonellaEnteritidis and Salmonella Muenster to 45 daysold squabs

\begin{tabular}{|l|l|l|l|l|l|l|l|}
\hline strain & $\begin{array}{l}\text { Inoculum } \\
(\mathrm{CFU} / \mathrm{ml})\end{array}$ & $\begin{array}{l}\text { No. of } \\
\text { Infected } \\
\text { squabs }\end{array}$ & $\begin{array}{l}\text { Incubation } \\
\text { period }\end{array}$ & $\begin{array}{l}\text { Total } \\
\text { No. of } \\
\text { Dead birds }\end{array}$ & $\begin{array}{l}\text { Mortality } \\
\text { rate }\end{array}$ & $\begin{array}{l}\text { No. of } \\
\text { Survival } \\
\text { birds }\end{array}$ & $\begin{array}{l}\text { Survival } \\
\text { rate }\end{array}$ \\
\hline SalmonellaTyphimurim & $4 \times 10^{8}$ & 10 & 5 days & 7 & $70 \%$ & 3 & $30 \%$ \\
\hline Salmonella Enteritidis & $4 \times 10^{8}$ & 10 & 6 days & 3 & $30 \%$ & 7 & $70 \%$ \\
\hline Salmonella Muenster & $4 \times 10^{8}$ & 10 & 4 days & 6 & $60 \%$ & 4 & $40 \%$ \\
\hline
\end{tabular}

\section{DisCUSSION}

Although paratyphoid disease is well known since 19th century as investigated by Moore (1895) paratyphoid infection is still Until now constitute one of the most important serious diseases of economic and zoonotic importance facing veterinarians in the field of pigeon diseases. The disease is responsible for severe losses due to lowering of fertility and hatchability. High mortalities in young ages which reach to $30 \%$, in addition to the chronically diseased birds act as a hazard to the other species of birds as well as to human being.

Until now there are few available information concerning the incidence of paratyphoid infections in pigeons in Upper Egypt. Therefore. The present study is dedicated to elaborate some aspects of paratyphoid infections in pigeons in Assiut governorate. The tools used in this investigation were studying the Incidence of paratyphoid infections in pigeons, Isolation and identification of the etiological agents, Molecular typing of the isolated Salmonella strains by using Polymerase Chain Reaction (PCR) technique, Studying the antibiogram of the isolated Salmonella strains to different antimicrobial agents available in the field as well as Studying the pathogenicity of the isolated Salmonella serotypes in 45 days old pigeon squabs.

The Incidence of paratyphoid infections among dead or sacrificed pigeons was investigated by collecting of 147 diseased birds suspected to be infected with Salmonella from different localities in Assiut province; these samples were subjected to post-mortem and bacteriological examinations.

The results of isolation showed that out of 147 freshly dead and sacrificed pigeons taken from different localities in assiut province only 18 
isolates with an incidence of (12.24\%). Our finding is nearly the same as El-Shater (1979) who reported an incidence of $12.4 \%$.

Our finding is less than that observed by other investigators as Ahmed and El-Sisi (1965), , Javedet al., (1994), Akbarmehr (2010), Rahman et al., (2011) and Hosainet al., (2012) who reported an incidence of $20.8 \% ; 17.83 \%$; $15.55 \%$; $26.66 \%$; and $35.71 \%$ respectively. On the other hand our finding is higher than that reported by Greguricet al., (1991), Georgiades and Iordanidis (2002), Mohamed (1999) and Mohamed (2008) who reported an incidence of $\%$; $8.6 \% ; 9.3 \%$ and $9.52 \%$ respectively. This decrease or increase in the incidence of isolation may be due to possibility of spreading of infection and remaining of the organism in the surrounding under the bad hygienic measures in some localities than others or to the number of samples examined or to the status of birds subjected to examination which may be diseased or apparently healthy or both, or to uncontrolled administration of antimicrobial agents. Mohamed (1999)

Salmonella strains obtained and identified were serotyped in to 3 serotypes namely Salmonella Typhimurium, Salmonella Enteritidis and Salmonella Muenster with the frequency of (66.6\%) for Salmonella, Typhimurium species, (27.7\%) for Salmonella Enteritidis species and $(5.55 \%)$ for Salmonella Muenster species so that $S$. Typhimurium and $S$. Enteritidis were the most frequent serotypes isolated. (S. typhimurium was the most frequently isolated serotype followed by $\mathrm{S}$. enteritidis) Our results supported by the findings observed by Georgiades and Iordanidis (2002) who isolated Salmonella Typhimurium and SalmonellaEnteritidis with frequency of $75.5 \%$; 11.3\% respectively and Mohamed (2008). Who isolated SalmonellaTyphimurium and SalmonellaEnteritidis with frequency of $88.5 \%$; $11.5 \%$ respectively and on the other hand disagrees with those reported by El-Agroudi (1963), Ahmed and El-Sisi (1965), Greguricet al., (1991) who isolated Salmonella Typhimurium as the only serotype isolated from all examined positive cases. And also disagrees with those reported byVerma and Gupta (1997) who isolated Salmonella Gallinarum as the only serotype isolated from pigeons And Yun et al. (2003) who isolated $S$. Montevideo as the most frequent serotype (16 strains), followed by 3 strains of $S$. Typhimurium. This may be attributed to uneven distribution of serotypes among countries, or to phenomenon commonly appeared around genus Salmonella which one serovar may be predominant for a number of years before it replaced by another serovar Jordan and pattison (1996) and Wray et al., (1996).

In this study we recorded the presence of invAgene in all examined samples as we examined seven representative samples taken from the all isolated strains (18 strains) belonged to SalmonellaTyphimurium (4 strains), SalmonellaEnteritidis (2 strains), and Salmonella Muenster (one strain) and all examined strains were positive for the presence of invA gene with $100 \%$ sensitivity and $100 \%$ specificity, the size of amplified product was 284bp (figure 2). Similar findings have been described by (Guoet al., 1999; Ferretti et al., 2001 and Schneider et al., 2002).

Antibiotics are considered one of the most important drugs nowadays used for animals and poultry not only from curative point but also from nutritional point. Strains of bacteria resistant to antibiotics emerge, even under controlled use of antibiotics claudet al., (1985). Recently multi-drug resistant (MDR) strains have emerged, presumably due to the extensive use of antimicrobial agents both in human and animals. In veterinary practice, antibiotics are used in livestock production, disease prevention and as growth-promoting feed additives (Swartz, 2002). The use of antibiotics in animals disrupts normal flora of intestine, resulting in to emergence of antibiotic-resistant Salmonellae and their prolonged faecal shedding into the environment (Threlfall, 2002).So the in vitro drug sensitivity test against bacterial isolates was done for selection of effective therapeutic measures and control (Rahman et al., 2004).

Periodic monitoring of Salmonella isolates to detect the drug resistance is recommended for revising the list of antimicrobial agents commonly used in poultry, so in a trial to test the different antimicrobial agents sensitivity against SalmonellaTyphimurium, Salmonella Enteritidis and Salmonella Muenster strains isolated from pigeons.the results revealed that all strains of Salmonella Typhimurium, SalmonellaEnteritidis and Salmonella Muenster were completely sensitive (100\%) to Amikacin and levofloxacin similar findings were observed by Yun et al., (2003),Banani et al., (2003), Selvarajet al., (2010),Rahman et al.,(2011) and Rahman et al., (2016) who reported a high sensitivity of Salmonella strains to Amikacin and levofloxacin. 
SalmonellaEnteritidis strains were completely sensitive to nor- floxacin. Similar findings were observed by Rahman et al., (1997), Mohamed (1999), Murugkaret al., (2005), and Jahantigh and Nili (2010) who reported a high sensitivity of Salmonella strains to nor-floxacin.

SalmonellaTyphimurium strains had variable sensitivity to Norfloxacin(58.34\%), Ceftizoxime $(58.34 \%)$ and Gentamycin $(41.67 \%)$ while both SalmonellaTyphimurium and Salmonella Enteritidis had variable sensitivity to Azithromycin (75\%, 80\% respectively), and Cefotaxime (83.34\%, 40\%Respectively), Ceftriaxone (58.34\%, 40\% respectively), and Ciprofloxacin (50\%, 60\% respectively) more or less similar findings were observed by Banani et al., (2003),Selvarajet al., (2010), Jahantigh and Nili (2010), Rahman et al. (2011) and Rahman et al., 2016.

Salmonella Typhimurium showed a variable degree of resistance to Doxycycline (83.34\%), Kanamycin $(83.34 \%)$ and Gentamycin $(50 \%)$. And SalmonellaEnteritidis showed a variable degree of resistance to Kanamycin (100\%), Doxycycline (80\%), Gentamycin (80\%), Cefotaxime (60\%), Ceftriaxone $(60 \%)$ and Ceftizoxime (60\%) more or less similar findings were observed by Rahman et al., (1997), Seyfarthet al., (1997), Murugkaret al., (2005), Jahantigh and Nili (2010) and Rahman et al. (2011).

Salmonella Muenster (one strain) was sensitive to Amikacin, levofloxacin, Azithromycin and Ceftriaxone and showed intermediate sensitivity to Cefotaxime, Gentamycin, Ceftizoxime and Doxycycline while showed resistance to Norfloxacin, Kanamycin and Ciprofloxacin.

In contrast of our results Selvarajet al., 2010 found high sensitivity of Salmonella isolates to kanamycin while he found high resistance against cefotaxime.

In this work, variations in resistance pattern among isolates of the same serotypes may be due to obtaining samples from different sites Mohamed (1999).

We can concluded from aforementioned results that Salmonella strains formed a various degree of resistance to most classical antibiotics, except drugs belonged to new generations of antimicrobial agents as fluoroquinolones and cephalosporins groups. So there has been a grown concern about Salmonella pathogens developing resistance to drugs which of very important value in explanation of drug treatment failure. Initially we observed that this problem of bacterial resistance can be solved by the application of new classes of drugs and at the same time the administration of therapeutic agents must not be described until sensitivity test firstly done. Mohamed (1999).

The purpose of experimental study was designed to describe the nature and sequential development of lesions on Salmonella infected pigeons and to determine the mortality rates.

The results of this experiment showed that SalmonellaTyphimurium, Salmonella Muenster and SalmonellaEnteritidis were pathogenic for 45-day-old squabs. The mortality rate was $70 \%$, $60 \%$ and $30 \%$ for SalmonellaTyphimurium, Salmonella Muenster and Salmonella Enteritidis respectively and SalmonellaTyphimurium was highly pathogenic to the pigeon squabs (Table 2). Mortalities started after 24-48 hours from the onset of clinical signs, reach peak at 3rd week and then gradually decreased. This finding may be supported by El-shater (1979) and Mohamed (1999) and on the other hand disagree with those described byUyttebroeket al., (1990), this may be due to the unsatisfactory conditions in their experiment. Mohamed (1999).

From the previously presented results, it is clear that there is variation in the virulence between SalmonellaTyphimurium, Salmonella Muenster and SalmonellaEnteritidis serotypes. These results are in agreement with those reported by Edwards et al., (1948) who recorded that Salmonella Typhimurium produced the highest percentage of deaths among experimentally infected chicks and El-shater (1979) who recorded the highest mortalities at the third week of infection and it varied from 10\%-100\% according to the serotype inoculated. Also our results are in agreement with those reported by Mohamed (1999) and Mohamed (2008) who reported a variation in the virulence between the different Salmonella serotypes examined in the experimental infection.

Experimental infection with Salmonella Typhimurium, Salmonella Muenster and SalmonellaEnteritidis to 45 day-old squabs resulted in more or less similar clinical signs characterized by loss of appetite, emaciation, thirsty, ruffled feathers, inclination to move , dullness, watery to mucoid greenish diarrhea, pasty vent, huddling together, drooped wings (figure 4), lameness and later on emaciation was observed. These clinical signs started to appear from 4th to 6th day post-infection. The clinical 
signs and their pattern of appearance is in agreement with those reported by other workers for experimental infection El-shater (1979), Uyttebroeket al., (1990), Mohamed (1999) and Mohamed (2008).

Acute septicaemic changes or lesions characteristic to choronic Salmonella infections were respectively seen in birds dying as early as 24 hours from the onset of the clinical signs or later on. These findings were congestion of liver, heart blood vessels and kidneys, catarrhal to severe haemorrhagic enteritis with enlargement of the liver. Greenish-brown and Bronzy discoloration of the liver in some cases was also observed (figures 5). In advanced stage of infection appeared pale areas of focal necrosis on the liver surface and lung, fibrinous perihepatitis and pericarditis ranged from mild to severe form were also observed. These gross pathological lesions were in agreement with those reported by El-shater (1979), Uyttebroeket al., (1990), Sato and Aoyagi (1996) and Mohamed (1999).

\section{CONCLUSION}

Paratyphoid Salmonella spp. are prevailing in pigeon farms at the study areas. The farms should be checked at regular intervals to know the status of Salmonella infection and the positive reactors should be eradicated, and biosecurity plan of the farms should be improved accordingly. In-vitro sensitivity test indicated that the isolates were sensitive toAmikacin, levofloxacin, norfloxacin and azithromycin. Multi-drug resistant (MDR) strains have emerged, due to the extensive use of antimicrobial agents both in human and animals so Periodic monitoring of Salmonella isolates to detect the drug resistance is recommended for revising the list of antimicrobial agents commonly used in poultry. The pathogenicity revealed that the examined strains of Salmonella Typhimurium, Salmonella Enteritidis and Salmonella Muenster proved highly pathogenic for pigeons causing considerable economic loss as a result of reduced body weight gain and high mortality.

\section{REFERENCES}

[1] Ahmed, A.A.S. and El-Sisi, M.A. (1965): Observation on diseases affecting pigeons in Egypt and their incidence with special reference to ornithosis, paratyphoid and trichomoniasis. Vet. Med. J. 7:319-330.

[2] Akbarmehr, J. (2010): Isolation of Salmonella spp. from poultry (ostrich, pigeon, and chicken) and detection of their hilA gene by PCR method. African Journal of Microbiology Research. 4 (24), 2678-2681.

[3] Banani, M.; Pourbakhsh, S. A.; Khaki, P. and Nikookhesal, G. H.(2003): Serotyping and drug sensitivity of Salmonella isolates from commercial chickens and domestic pigeons submitted to Razi institute. Pajouhesh-vaSazandegi. In Animal Sciences. 59, 92-99.

[4] Bauer AW; Kirby MM; Sherris JC; Truck M.(1966): Antibiotic susceptibility testing by a standardized single disk method. Am J ClinPathol; 45: 493-6.

[5] Begum K.; Reza T.A.; Hague M.; Hossain A.; Hassan F.M.K.; Hassan S.N.; Akhter N.; Ahmed A.; and Barua U. (2010): Isolation, Identification and antibiotic resistance pattern of SalmonellaSpp. from chicken egg ,intestines and environmental samples. Bangladesh Pharmaceut. J, 13:23-27.

[6] claud,S.S.; Rosenberger, K.; Fries, P.A.; Wilson, R.A. and Odor, E.M. (1985): In-vitro and in-vivo characterization of avian E.coli.1Serotypes, metabolic activity and antibiotic sensitivity. Avian Diseases. 29: 1084-1093.

[7] Clavijo, R. I.; Cindy, L., Gary, L. A.; Riley, L.W. and Sangwei, L. (2006): Identification of Genes Associated with Survival of Salmonella enteric SerovarEnteritidis in Chicken Egg Albumen. Applied and Environmental, Microbiology, 72 (2): 1055-106.

[8] Edwards, P. R.; Bruner, D. W. and Moran, A. B. (1948): Salmonella infections of fowl. Cornell Vet. 38:247-256.

[9] El-Agroudi, M.A. (1963): Further studies on salmonellosis in Domestic and Game birds in UAR. $4^{\text {th }}$. Arab. Ann. Vet. Cong. Cairo, UAR. pp. 129-142.

[10] El-Shater, S.A. (1979): Studies on paratyphoid infections in pigeons. M.V.Sc., Thesis, (poult. Dis.), Fac. Vet. Med., Cairo University.

[11] Ferretti, R.; Mannazzu, I.; Cocolin, L., Comi, G. and Clementi, F. (2001):Twelve-hour PCRbased method for detection of Salmonella spp. in food Appl Environ Microbiol. 67(2):977978.

[12] Georgiades, G. K. and Iordanidis, P. (2002): Prevalence of Salmonella infection in pigeons, canaries and psittacines. Deltiontes Ellenikes Kteniatrikes Etaireias = Journal of the Hellenic Veterinary Medical Society. 53 (2): 113-118.

[13] Greguric, J.; Muzlnic, J.; Tompak, B.; Kalenic, S. and Sipus, D.(1991):Campylobacter jejuni, SalmonellaTyphimurium and Mycobacterium avium intracellular in pigeons from different ecological environments. VeterinaiskiArhiv. 61 (4): $217-224$

[14] Guo, L.; Killefer J.; Kenney P.B. and MickMorris, J.D. (1999): Use of arbitrarily primed polymerase chain reaction to study Salmonella 
ecology in a turkey production. Environment. Poult. Sci., 78: 24-31.

[15] Hosain, M. S.; Islam, M. A; Khatun M. M. ; Dey, R. K.(2012): Prevalence and Antibiogram Profiles of Salmonella Isolated from Pigeons inMymensingh, Bangladesh.Microbes and Health, 1(2): 54-57

[16] Humphrey, T. J. (2006):Public health aspects of Salmonella enterica in food production. In Mastroeni, P. and Maskell, D. Salmonella Infections: Clinical, Immunological and Molecular Aspects (pp. 89 -115). Cambridge: Cambridge University Press.

[17] Ibrahim, H.M.; El-Moaty, D.A.; Ahmed, HA.; El-Enbaawy, M.I.; (2016) Phenotypic and genotypic characterization of locally isolated Salmonella strains used in preparation of Salmonella antigens in Egypt. Vet World. 2016;9(12):1435-9.

[18] ISO 6579 (2002): Microbiology of food and animal feeding stuffs. Horizontal method for the detection of Salmonella species. ( $4^{\text {th }}$ ed.) International Organization for Standardization

[19] Jahantigh, M. and Nili, H. (2010): Drug resistance of Salmonella spp. isolated from pigeon eggs. Comparative Clinical Pathology. 19: 4, 437-439.

[20] Javed, T., Siddique, M. and Hameed, A. (1994): occurrence of salmonella in Avifauna. Pakistan Vet. J. 14(4):254-257.

[21] Jordan, F. T. W., and pattison, M. (1996): Poultry Diseases. $4^{\text {th }}$ ed., University Press, Cambridge, Great Britain.

[22] Kauffmann, G. (1974):Kauffmann white scheme. J. Acta. Path. Microbiol. Sci., 61:385.

[23] Mohamed, M. A. (1999): Studies on paratyphoid infections in pigeons. M.V.Sc. thesis, poultry diseases, Fac. Vet. Med., Assiut University.

[24] Mohamed, M. A. (2008): A study on genetic variability on salmonella strains isolated from pigeons using entero bacterial repetitative integrated consensus-PCR (ERIC-PCR) and plasmid profiling. XIII Scientific Congress, Faculty of Veterinary Medicine, Assuit University.

[25] Moore, V. A(1895): On a pathogenic bacillus of the hog-cholera group associated with a fatal disease in pigeons. USDA BAI Bull 8, pp.7176. Cited by Nagaraja, K.V., Promeroy, B.S. and Williams, J.E. (1991) In: Diseases of poultry $9^{\text {th }}$ ed. Calnek, B.W.; Barnes, H.J.; Beard, C.W.; Reid, W. M. and Yoder, H. W., Jr. eds. Iowa State University Press, Ames, Iowa, pp. 99-137.

[26] Murugkar, H.V.; Rahman, H.; Kumar, A. and Bhattacharya, D.(2005): Isolation, phage typing, and antibiogram of Salmonella from man and animals in northeastern India. Indian $\mathbf{J}$ Med .Res. 122:237-242.

ARC Journal of Animal and Veterinary Sciences
[27] NCCLS (2003): Performance Standards for Antimicrobial Disk Susceptibility Tests; $8^{\text {th }}$ d . Approved Standard M2-A8. NCCLS, Wayne, Pa.

[28] Quinn, P.J.; Markey, B.K.; Carter, M.E.; Donnelly, W.J. and F.C. Leonard, (2002) : Veterinary Microbiology and Microbial Diseases. $1^{\text {st }}$ ed., Wiley-Blackwell Science, USA, ISBN-13: 978-0632055258, Pages: 544.

[29] Rahman, M. M.; Hossain, M. K.; Akhter, M. R.; Hasan, S. M. K. and Rahman, M. M. (2011): Characterization and antibiogram study of Salmonellaserovars isolated from duck, quail and pigeon in Dinajpur district of Bangladesh. International Journal of Sustainable Agricultural Technology. 7: 2, 23-29.

[30] Rahman, M. M.; Rahman, M.M.; Meher, M.M.; Khan, M.S.I.; Anower, A.K.M.M. (2016) :Isolation and antibiogram of Salmonella spp. from duck and pigeon in Dinajpur, Bangladesh. Journal of Advanced Veterinary and Animal Research. 2016; 3(4):386-391. https://doi.org/ 10.5455/javar.2016.c177

[31] Rahman, M.A.; Samad, M.A.; Rahman, M.B. and Kabir, S.M.L. (2004):Bacterio-pathological studies on salmonellosis, colibacillosis and pasteurellosis in natural and experimental infections in chickens. Bangl. J. Vet. Med., 2, 1-8.

[32] Rahman, N.;Barman, N.N.; Patgiri, G. P. and Kalita, N. (1997): Outbreak of salmonellosis in broiler flocks in Assam. Indian J. of Comp. Microbiol. Immun. And Infectious Diseases. 18:56-58.

[33] Salehi, T.Z.; Mahzounieh, M. and Saeedzadeh, A. (2005): Detection of InvA Gene in Isolated Salmonella from Broilers by PCR Method. Int. J. Poultry. Sci. 4(5): 557-559.

[34] Sato, Y. and Aoyagi, T. (1996): Infectivity and persistence of Salmonella typhimurium for (Poephilaguttata) isolated from the same species. J. Vet. Med. Sci. 58: 845-848.

[35] Schneder, A.; Gronewald, C.; Fandke, M.; Kurth, B.; Barkowski, S. and Berghof - ager, K.(2002): Real-time detection of the genus Salmonella with the Light Cycler system. Biochemica., 4: 19-21.

[36] Selvaraj, R.; Das, R.; Ganguly, S.; Ganguli, M.; Dhanalakshmi, S. and Mukhopadhayay, S.K.(2010): Characterization and antibiogram of Salmonella spp. from poultry specimens. J. Microbiol. Antimicrobials. 2(9): 123-126.

[37] Seyfarth, A.M.; Wegener, H.C. and FrimodtM.N. (1997): Antimicrobial resistance in Salmonella enterica subsp. Enterica serovartyphimurium from humans and production animals. J. Antimicrob. Chemother., 40:67-75.

[38] Swartz, M.N., (2002): Human diseases caused by foodborne pathogens of animal origin. Clin. Infect. Dis. 34, S111-S122. 
[39] Taha, F.A. (2003):The Poultry Sector in Middle-Income Countries and Its Feed Requirements: The Case of Egypt. Agriculture andTradereports.http://usda.mannlib.cornell.ed u/usda/ers/WRS//2000s/2003/WRS-12-30-2003 _Special_Report.pdf.

[40] Threlfall, E.J. (2002): Antimicrobial drug resistance in Salmonella: problems and perspectives in food- and water-borne infections. FEMS Microbiol. Rev. 26: 141-148.

[41] Tudor, C. D. (1991): Pigeon health and Diseases. $1^{\text {st }}$ ed. Iowa State University Press, Ames, Iowa, USA. Pp. 54-60.

[42] Uyttebroek, E.; Gevaert, D. and Deriese, L. A. (1990): Effect of different chemotherapeutics on experimental salmonellosis in pigeons. Vlaams DiergeneeskdTijdschr., 58:51-54.
[43] Verma, J. C. and Gupta, B. R. (1997): Prevalence of Salmonella serotypes of avian origin (in India). Indian J. of Comp. Microbiology, Immunology and infectious Dis., 18 (1) $52-55$.

[44] Wray, C.; Davies, R.H. and Evans S.J. (1996): Salmonella infection in poultry: the production environment. In: Poultry Meat Science. Richardson R.I. and. Mead, G.C. 25 ${ }^{\text {th }}$ Poultry Science Symposium, University of Bristol, pp 257.

[45] Yun GaRi; Lee YoungJu; Kim KiSeuk and TakRyunBin (2003) Biochemical characteristics and plasmid profiles of Salmonella isolated from wild birds in Daegu area. Korean Journal of Veterinary Public Health. 27: 2, 59-67.

Citation: Alhussien M Gaber, Ahmed I. Ibrahim, Soad A Nasef, Nabila Osman. Pathogenicity Characterization and Antibiogram of Paratyphoid Isolates from Pigeons in Upper Egypt. ARC Journal of Animal and Veterinary Sciences. 2019; 5(3):10-20. doi: dx.doi.org/10.20431/2455-2518.0503002.

Copyright: (C) 2019 Authors. This is an open-access article distributed under the terms of the Creative Commons Attribution License, which permits unrestricted use, distribution, and reproduction in any medium, provided the original author and source are credited. 